\title{
PAZ E EQUILÍBRIO NAS RELAÇÕES FAMILIARES: DAS OFICINAS SISTÊMICAS E DE PARENTALIDADE ÀS AUDIÊNCIAS DE CONCILIAÇÃO E SESSÕES DE MEDIAÇÃO - PRIMEIRAS IMPRESSÕES
}

\author{
PEACE AND BALANCE IN FAMILY \\ RELATIONS: FROM SYSTEMIC \\ WORKSHOPS AND PARENTING TO THE \\ CONCILIATION HEARINGS AND MEDIATION \\ SESSIONS - FIRST IMPRESSIONS
}

\section{Camila Carolina Mafra Martins ${ }^{1}$}

Resumo: Com o presente trabalho busca-se demonstrar que o sistema judicial brasileiro tem contribuído para a evolução da garantia da ordem jurídica justa e do acesso à justiça, através dos meios autocompositivos de solução de conflitos, bem como, estimulando as práticas restaurativas, permitindo que o conflito entre as partes tenha um tratamento adequado e diferenciado. Além disso, com este artigo objetiva-se mensurar, especificamente nos processos de natureza familiar, a aplicação de instrumentos, como a implementação de palestras e oficinas, com abordagem sistêmica, além de outras ferramentas, que aliadas às audiências de conciliação e sessões de mediação possibilitam uma prestação jurisdicional mais eficaz e célere.

Palavras chave: Conciliação. Mediação. Direito Sistêmico no Judiciário.

Abstract:This research aims to demonstrate how the Brazilian judicial system has contributed eminently for the betterment and guarantee of a just legal order system and of people's access to justice through a consensual process of solving conflicts, as well as

1 Pós- graduanda em direito de família e das sucessões, nível de especialização pela Universidade Anhanguera-Uniderp, por meio da rede LFG, aluna do Módulo I da Escola Superior da Magistratura no Estado de Santa Catarina (ESMESC), extensão de Itajaí, SC. Bacharela em Direito pela Universidade do Vale do Itajaí (UNIVALI), conciliadora judicial e palestrante da Oficina de Parentalidade na Comarca de Camboriú, SC. Email: camilacmmartins@gmail.com. 
stimulating restorative practices, allowing the conflict between the parties to be handled with an appropriate and differentiated treatment. In addition, this research aims to measure, specifically in the processes of family nature, the application of instruments, such as the implementation of lectures and workshops, through a systemic approach, as well as other tools that, allied with conciliation hearings and mediation sessions enable more effective and speedy judicial review.

Keywords: Conciliation. Mediation. Systemic Right in the Judiciary.

\section{INTRODUÇÃO}

A finalidade deste estudo dedica-se à observação das oficinas implantadas na comarca de Camboriú - SC, Brasil, nas quais as partes envolvidas nos processos de natureza familiar participam, antes da realização da audiência de conciliação ou mediação.

Para tanto, estabelece-seinicialmente, de forma simples, a diferença entre conflito, inerente à natureza humana e da formação do litígio, que inicia quando a divergência entre as partes se transforma em uma demanda judicial. Esta consideração inicial é importante para demonstrar que a cultura tradicional do sistema é terceirizar a solução dos litígios.

Adiante, se faz um breve comentário histórico-comparativo do sistema judicial americano e brasileiro, delineando assim, um parâmetro de origem temporal e demonstrando que estes instrumentos alternativos de resolução de conflitos serviram como referência ao Brasil.

Conjuntamente, pontua-se a questão da criação de políticas públicas, por iniciativa do Judiciário, promovendo um sistema judicial humanizado com prevenção e solução adequada de conflitos, que impulsionou as práticas consensuais. Em seguida descreve no que consiste a conciliação e mediação.

Por fim, encerra-se com aspectos práticos sobre as oficinas, como são desenvolvidas e seus reflexos nas audiências de conciliação e mediação realizadas na $1^{\text {a }}$ Vara Cível da Comarca de Camboriú. 


\section{ESTRUTURA DO CONFLITO}

Para explorar de forma mais produtiva as técnicas autocompositivas, faz-se necessário conceituar conflito, bem como, diferenciá-lo de litígio.

Discordâncias são registradas desde o início da humanidade, em todas as nações e comunidades, o conflito é afeto às relações e à sociedade, seja no âmbito pessoal, familiar ou de trabalho. (MOORE, 1998).

Para Castro Junior: "O conflito ocorre quando as pessoas definem sua posição, reagindo a uma infração no seu relacionamento." (CASTRO JUNIOR, 2002, p.49). Nesse segmento, Crain e Edelman se posicionam de forma semelhante:

E também não é mera coincidência o fato da cultura ocidental tradicionalmente tratar a ambas com suspeita, uma vez que sua visão de conflito é a de uma situação de batalha em que um lado não pode vencer sem que o outro perca, $\mathrm{e}$ que prefere culpar o oponente a assumir sua responsabilidade pessoal pelas contribuições para o problema existente. (CRAIN, EDELMAN, 1996, p.25).

A concepção mais propagada de conflito, é aquela onde há uma situação na qual duas ou mais pessoas não acordam acerca das ações ou decisões uma da outra, normalmente é associado à crise ou batalha, na qual um está correto e o outro errado, em regra, é tido como algo negativo, indesejável e prejudicial.

No entanto, a visão moderna da teoria conflito, em razão deste ser inevitável e natural às relações humanas, dá ao conflito um aspecto positivo, e, concebe que mesmo com a discordância, pode-se evoluir, crescer, mudar paradigmas, e sobretudo, encontrar soluções. Ávila compactua com esse raciocínio quando aduz que:

O conceito chinês para a palavra conflito é composto por dois sinais superpostos: um quer perigo e o outro oportunidade. O perigo é permanecer num impasse que retira as 
energias individuais; a oportunidade é considerar as opções e abrir-se as energias individuais; a oportunidade é considerar as opções e abrir-se a novas possibilidades que vão permitir novas relações entre os indivíduos e inventar meios de solucionar os problemas cotidianos. (ÁVILA, 2004, p.77).

Partindo desse pressuposto, é sabido que o conflito é um elemento constitutivo da vida, e tanto tem sentido de crise (destrutivo), quanto de oportunidade (construtivo), partindo desse axioma, denota-se que o conflito não necessariamente, exige que seja evitado ou extinto, mas sim, conduzido de forma cooperativa e eficaz. A solução mais eficaz para o conflito é aquela que é tomada pelas partes. Em consonância com essa ideia, Quitéria Peres traz o seguinte pensamento:

Afinal, a experiência do conflito não precisa ser vivenciada num campo de confronto (como se um ringue fosse), pois seu resultado, diferentemente de uma luta, não precisa revelar um vencedor e um perdedor. Ao resolvê-lo conjuntamente, ambas as partes se beneficiam segundo os parâmetros por ela definidos. (PERES, 2018, p. 22).

Por fim, percebe-se pelo entendimento majoritário da doutrina predominante, que a diferença é puramente técnica, ou seja, o conflito é o desentendimento interpessoal, a oposição de interesses, pensamentos, sentimentos ou ideias, já o litígio passa a existir quando a diferença entre as partes ou o conflito de interesses é judicializado, se materializando na propositura da demanda.

\section{FORMAÇÃO DO LITÍGIO}

A classificação do litígio é desdobrada em duas correntes na doutrina pátria, a primeira aduz que o litígio é formado no momento em que a divergência de pretensões dá origem ao processo, a segunda corrente sugere que inicia com a resistência da pretensão, na forma de contestação da demanda, constituindo deste modo, o controverso jurídico.A distinção é relevante somente para semântica, logo, não implica diferença de 
resolução na prática.

Com o advento da Constituição da República, em 1988, e a consolidação de um direito básico, que garantiu o acesso à justiça de forma igualitária e inclusiva para todos, tornou o poder jurisdicional do Judiciário a forma tradicional de resolução de conflitos.

À vista disso, quando não conseguem sozinhas, dar fim aos seus conflitos, as partes abdicam de buscar uma solução pacífica e preconizam a lide à autoridade do Estado, submetendo o litígio a análise de um terceiro, não implexo no conflito. Através da jurisdição, utilizando-se de normas e artigos, incubirá ao Juiz que diga da decisão acerca do objeto da lide, para Cintra, Grinover e Dinamarco:

Pelo que já ficou dito, compreende-se que o Estado moderno exerce seu poder para a solução dos conflitos interindividuais. O poder estatal, hoje, abrange a capacidade de dirimir os conflitos que envolvem as pessoas (inclusive o próprio Estado), decidindo sobre as pretensões apresentadas e impondo as decisões. (CINTRA, GRINOVER, DINAMARCO, 2002, p.24).

No entanto, no litígio as partes envolvidas não detém o domínio dos atos processuais, ficando condicionadas ao risco que não sejam satisfeitos seus interesses, Schlichting alerta para isso quando diz que:

Dado o princípio da disponibilidade, segundo o qual podem as partes abrir mão de parte ou de todo o direito em litígio, tendo em vista que o juiz deve decidir de acordo com o alegado e provado pelas partes, e dado que é direito das partes provar somente aquilo que lhes interesse, pelo próprio princípio da disponibilidade, a verdade que se alcança, em alguns casos, é a verdade formal, daquilo que está nos autos, ainda que esta não represente a verdade absoluta. (SCHLICHTING, 2002, p.17).

Ademais, outro aspecto importante é o desgaste emocional 
que um processo judicial pode causar, especialmente quando as ações versam sobre as relações familiares, em que as questões vão muito além de aspectos jurídicos tutelados. Sobre este fato, o Juiz André Gomma de Azevedo, muito bem declarou:

As partes, quando buscam auxílio do Estado para solução de seus conflitos, frequentemente os têm acentuados ante procedimentos que abstratamente se apresentam como brilhantes modelos de lógica jurídica-processual - contudo, no cotidiano, acabam por frequentemente se mostrar ineficientes na medida em que enfraquecem os relacionamentos sociais preexistentes entre as partes em conflito. Exemplificativamente, quando um juiz de direito sentencia determinando com quem ficará a guarda de um filho ou os valores a serem pagos a título de alimentos, põe fim, para fins do direito positivado, a um determinado litígio; todavia, além de não resolver a relação conflituosa, muitas vezes acirra o próprio conflito, criando novas dificuldades para os pais e para os filhos. Torna-se claro que o conflito, em muitos casos, não pode ser resolvido por abstrata aplicação da técnica de subsunção. Ao examinar quais fatos encontram-se presentes para em seguida indicar o direito aplicável à espécie (subsunção), o operador do direito não pode mais deixar de fora o componente fundamental ao conflito e sua resolução: o ser humano. (AZEVEDO, 2013, p.248).

A prolação de uma sentença pode pôr um fim ao litígio, mas nem sempre, alcançará a pacificação de um conflito. Em contrapartida, a cultura dos métodos não adversariais delega aos interessados a decisão do problema, possibilitando que as pessoas envolvidas participem ativamente na busca de melhores soluções, legitimando e empoderando o cidadão como competente para solucionar seus conflitos na busca da pacificação social.

\section{MEIOS CONSENSUAIS DE RESOLUÇÃO DE CONFLITOS}

Desde os tempos bíblicos é possível perceber que os méto- 
dos alternativos eram aplicados para resolver diferenças civis e religiosas, e foram repassados a outras culturas do mundo, como a islâmica, cristã, judaíca, hinduísta, budista, confucionistas e indígenas.

Posteriormente, se difundiu na América e em outras colônias, de início os Estados Unidos, passaram a desenvolver procedimentos alternativos para a resolução de disputas de natureza informal e involuntária, que eram aplicados paralelamente as estruturas preexistentes de solução de conflitos dos povos americanos nativos.

Destaca-se que as técnicas alternativas de resolução de conflitos não surgiram nos Estados Unidos, e, foram aperfeiçoadas por este, posto que em 1976 durante a Conferência sobre a Insatisfação Pública para com o Sistema de Justiça, como resposta a problemática, foi apresentado os primeiros projetos e, posteriormente, os métodos foram introduzidas em seu ordenamento jurídico.

Acerca dessas técnicas, intituladas de Alternative Dispute Resolution (ADR), surgem como alternativas e meios adequados de solução de conflitos, vêm com a finalidade de se evitar que os conflitos sejam transformados em demandas judiciais. Castro Junior faz a seguinte observação:

Os métodos alternativos de resolução de conflitos são chamados nos Estados Unidos de Alternative Dispute Resolution $(A D R)$ e designam todos os processos de resolução de disputas sem intervenção judicial, tido como último recurso não violento para resolver uma disputa. $(2008$, p.82).

O mesmo autor (2008, p.191) relata que a disseminação das técnicas de Alternative Dispute Resolution, nas esferas privada e pública, nos Estados Unidos, causaram um notável impacto na jurisdição e reduziram drasticamente o número de processos nos tribunais. 
Percebe-se que nos Estados Unidos, não só os cidadãos, como também aqueles que trabalham pela justiça, procuram procedimentos simplificados e de fácil acesso, assim ensina Castro Junior:

Por outro lado, a cultura jurídica norte-americana tem maior tradição na procura e implementação de métodos alternativos para resolver os seus conflitos do que a brasileira, uma vez que figuras eminentes da história norte-americana, inclusive com formação jurídica, há tempos já desencorajavam a litigância ou estimulavam a procura de soluções alternativas para resolver os conflitos, como se denota dos pensamentos de Abraham Lincoln, em 1850: "Desestimule a litigância. Procure fazer com que os seus vizinhos façam sempre um acordo. Demonstre a eles que o vencedor é constantemente um verdadeiro perdedor em honorários advocatícios. Custas judiciais e tempo. (CASTRO JÚNIOR, 2008, p.191).

Partindo desse mesmo pressuposto, o sistema brasileiro incorporou diversos institutos do sistema judicial norte-americano, readaptados a sua cultura jurídica, promovendo uma justiça democrática e participativa, mais ampla do que a tradicional, excedendo os limites da jurisdição e do poder judicial.

Diante dessa premissa de consensualismo, o Poder Judiciário no Brasil, passa a desenvolver pequenas mudanças em seu mecanismo processual, inserindo a conciliação nos Juizados Especiais Cíveis, com a criação da Lei n. 9.099/95. Na década seguinte, surgem inúmeros projetos e iniciativas que priorizam a autocomposição.

Constata-se então, os resultados positivos dos projetos, à vista disso, criam-se políticas públicas de tratamento adequado dos problemas jurídicos e dos conflitos de interesses, estimulando os mecanismos de solução de conflitos.

Surge então, a Política Nacional de Conciliação, instituída através da Resolução n. 125, de 29 de novembro de 2010, 
do Conselho Nacional de Justiça, dispondo como objetivo sistematizar e difundir as práticas de resolução e prevenção adequadas de conflitos, especialmente os consensuais, como a conciliação e a mediação.

Demonstra-se nas justificativas da referida resolução, que a conciliação e a mediação, no tocante a solução e a prevenção de litígios, em programas já aplicados nos Tribunais, reduziram a excessiva judicialização, minimizando ainda, a quantidade de execuções de sentenças e de recursos.

Percebe-se ainda, que os métodos não adversariais criam condições para que as pessoas em conflito possam deparar na pessoa do mediador ou do conciliador, um profissional neutro, capaz de conduzir, sem impor uma decisão, assim, as partes podem construir juntas, soluções adequadas as suas necessidades.

Além disso, outra vantagem do uso de tais métodos decorre da redução dos custos judiciais e celeridade para a solução do caso, possibilitando um amplo acesso à justiça, nessa linha, Moore afirma:

Devido ao caráter nocivo do conflito e aos custos físicos, emocionais e financeiros que freqüentemente resultam das disputas, as pessoas têm sempre buscado maneiras de resolver suas diferenças. Ao procurar administrar e resolver suas diferenças, têm tentado desenvolver procedimentos que sejam eficientes que lhes permitam satisfazer seus interesses, que minimizem seus sofrimentos e que controlem gastos desnecessários de recursos. (MOORE, 1998, p.18).

Sobre este prisma Capelletti e Garth têm o mesmo entendimento:

Existem vantagens óbvias tanto para as partes quanto para o sistema jurídico, se o litígio é resolvido sem a necessidade de julgamento. A sobrecarga dos tribunais e as despesas excessivamente altas com os litígios podem tornar particularmente benéficas para as partes as soluções rápidas e mediadas. (CAPELLETTI, GARTH, 1998, p.83). 
Apesar da promessa de soluções mais rápidas e menos onerosa, em comparação aos processos judiciais, as práticas consensuais ainda vão além desses benefícios, pois sugerem uma outra forma de compreensão dos conflitos das partes e autocomposição.

\subsection{Conciliação}

Em continuidade pela consagração deste movimento, o Código de Processo Civil passa por modificações em 2015, e nos seus princípios norteadores, incentiva que as práticas de solução consensual de conflitos devem ser estimuladas por juízes, advogados, defensores e membros do Ministério Público.

Devidamente disciplinada pelo artigo 334 do Código de Processo Civil, a audiência de conciliação, inaugura uma fase conciliatória no procedimento, o texto legal diz que, quando a inicial preencher os requisitos legais e não for improcedente o pedido liminar, o juiz designará audiência de conciliação ou mediação, com antecedência mínima de trinta dias, devendo o réu ser citado com pelo menos vinte dias de antecedência.

Desta forma, a finalidade foi priorizar a conciliação, nos processos em que houver questões de direito disponível. O legislador estabelece ainda, que a conciliação poderá ser desdobrar em outras sessões, se assim for necessário para a composição das partes, desde que não exceda a dois meses da realização da primeira audiência.

A conciliação, para Plácido e Silva, significa: "Conciliação derivado do latim conciliatio, de conciliare (atrair, harmonizar, ajuntar), entende-se o ato pelo qual duas ou mais pessoas desavindas a respeito de certo negócio, ponham fim à divergência amigavelmente". Para o Conselho Nacional de Justiça, conciliação é:

A Conciliação é um método utilizado em conflitos mais 
simples, ou restritos, no qual o terceiro facilitador pode adotar uma posição mais ativa, porém neutra com relação ao conflito e imparcial. É um processo consensual breve, que busca uma efetiva harmonização social e a restauração, dentro dos limites possíveis, da relação social das partes. (BRASIL, 2010).

Um dos objetivos da conciliação é dar fim à controvérsia em si mesma, através de concessões mútuas, do reestabelecimento do diálogo entre as partes e da harmonização das relações, construindo assim a resolução que satisfaça ambas as partes, protagonistas do processo. Castro Júnior conceitua a conciliação da seguinte forma:

É essencialmente uma tática psicológica, conduzida por uma terceira parte que procura obter percepções, para reduzir medos sem fundamentos e melhorar a comunicação entre as partes, a fim de permitir uma discussão racional que possibilite, assim, um acordo razoável, perpassando a negociação e a mediação. (CASTRO JUNIOR, 2002, p.96).

Desta forma, tem-se com a conciliação uma ferramenta eficiente para a solução de desacordos em todos os tipos de demandas e partes, principalmente porque recompõe a relação entre as partes, em vez de julgar as partes vencedoras ou vencidas. (CAPPELETTI, 1998).

A conciliação e a mediação são práticas distintas, entretanto, são muito confundidas, o Manual de Mediação Judicial, as diferencia da seguinte forma:

[...] a mediação é definida como um processo no qual se aplicam integralmente todas as técnicas autocompositivas e no qual, em regra, não há restrição de tempo para sua realização. Naturalmente, há um planejamento sistêmico para que o mediador possa desempenhar sua função sem tais restrições temporais. Por outro lado, a conciliação, também, para fins deste manual, pode ser definida como um processo autocompositivo ou uma fase de um processo heterocompositivo no qual se aplicam algumas técni- 
cas autocompositivas e em que há, em regra, restrição de tempo para sua realização. Alguns autores distinguem a conciliação da mediação indicando que naquele processo o conciliador pode apresentar uma apreciação do mérito ou uma recomendação de uma solução tida por ele (mediador) como justa. Por sua vez, na mediação tais recomendações não seriam cabíveis. (BRASIL, 2013).

Sendo assim, a conciliação possibilita o acesso à justiça de forma efetiva, célere e desburocratizada, sustenta a pacificação social, a solução e a prevenção dos litígios, como consequência, reduz o número de processos, execuções e recursos.

\subsection{Mediação}

O mundo vem passando por inúmeras e incontáveis mudanças nos aspectos sociais, políticos e econômicos, e em muitas dessas transformações, a mediação tem sido amplamente utilizada, marcando assim, a relevância dessas técnicas no desenvolvimento dos povos.

Ao tempo que o processo judicial aparta e antagoniza as partes, a mediação tem por desígnio sustentar o igualitarismo e o exercício da responsabilidade, Moore explica que:

A mediação é geralmente definida como a interferência em uma negociação ou em um conflito de uma terceira parte aceitável, tendo um poder de decisão limitado ou não-autoritário, e que ajuda as partes envolvidas a chegarem voluntariamente a um acordo, mutuamente aceitável com relação às questões em disputa. Além de lidar com questões fundamentais, a mediação pode também estabelecer ou fortalecer relacionamentos de confiança e respeito entre as partes ou encerrar relacionamentos de uma maneira que minimize os custos ou danos psicológicos. (MOORE, 1988, p.18).

A mediação visa, por meio do diálogo e da investigação dos problemas e as reais motivações das partes envolvidas, alcançando assim, uma compreensão do conflito e das neces- 
sidades a serem satisfeitas, na concepção de Serpa, mediação é definida desta forma:

É um processo informal, voluntário, onde um terceiro interventor, neutro, assiste os disputantes na resolução de suas questões, pautado na autodeterminação das partes. O papel do interventor é ajudar na comunicação, através de neutralização de emoções, formulação de opções e negociação de acordos. (SERPA, 1998, p.360).

Deve-se ressaltar que as pessoas em circunstância da situação de conflito, tendem a defender seus interesses, apresentando posições, como por exemplo: "eu quero isso" ou "só aceito tal coisa, só aceito se for assim", no entanto, esta atitude pode não ser a de representação dos interesses, que criam entraves para a solução da real necessidade dos envolvidos, Castro Junior ensina:

Um conceito menos formal é o de que se trata de um processo no qual se objetiva fazer com que as partes conheçam os interesses e as necessidades de cada uma e que, através do qual, o acordo e a divergência sejam cuidadosamente explorados, e as opções e propostas discutidas. Além disso, os interesses das partes devem ser apresentados e apreciados, de modo que o mediador, como um facilitador neutro, possibilita por meio das negociações entre as partes a auto composição do conflito. Usando a mediação pode-se resolver o conflito pela via do conhecimento dos interesses e das necessidades que estão por detrás das posições das partes envolvidas. (CASTRO JUNIOR, 2002, p.93).

Por isso, o mesmo autor, descreve que, as partes poderão, com o auxílio do mediador, compreendendo os interesses e necessidades, buscar juntos, a melhor solução para o caso. (2002, p.93).

A mediação é uma alternativa efetiva, que permite a comunicação entre as partes, e provoca transformações em procedimentos respaldados pela autonomia de vontades, sem a impo- 
sição de uma decisão de um terceiro. Para Warat, a mediação:

Seria uma proposta transformadora do conflito, porque não busca a decisão por um terceiro, mas, sim, a sua resolução pelas próprias partes, que recebem auxílio do mediador para administrá-lo. A mediação não se preocupa com o litígio, ou seja, com a verdade formal contida nos autos. Tampouco, tem como única finalidade a obtenção de um acordo. Mas, visa, principalmente, ajudar as partes a redimensionar o conflito, aqui entendido como conjunto de condições psicológicas, culturais e sociais que determinaram um choque de atitudes e interesses no relacionamento das pessoas envolvidas. (WARAT, 2001, p.81).

Sem desconsiderar as implicações legais que advém de um processo judicial, a mediação, ao invés de favorecer as longas e exaustivas pelejas judiciais, pode ser empregada para ratificar os acordos que serão reciprocamente aceitáveis, Vezzula doutrina esse aspecto: "A mediação oferece um ambiente propício para que duas ou mais pessoas envolvidas num conflito possam dialogar sobre ele assumindo uma conduta cooperativa e pacífica." (VEZZULA, 2011, p.11).

É de suma importância destacar que a mediação não pode confundir-se com a arbitragem, tampouco com qualquer forma de terapia ou aconselhamento, Castro Junior adverte:

Deve-se ressaltar que a mediação não é julgamento baseado na intervenção, tal como a arbitragem ou litígio, nem é aconselhamento ou conciliação. Além disso, não se confunde a mediação feita no divórcio com o aconselhamento do casamento, bem como não se deve fazer mediação quando uma das partes está em crise. (CASTRO JUNIOR, 2002, p.95).

Cinco anos após a Resolução n. 125, do Conselho Nacional de Justiça (CNJ), é publicado, em 18 de março de 2015 o "Novo Código de Processo Civil", por sua vez, em 26 de junho de 2015 é sancionada a Lei n. 13.140, conhecida como lei da mediação, que entrou em vigor em dezembro daquele ano. 
Não obstante, as ações de natureza familiar receberam atenção diferenciada no Código de Processo Civil, com a preferência pelos meios consensuais e autocompositivos, que proporciona meios para que o respeito entre as partes, o equilíbrio nas relações e a restauração de laços afetivos, sejam abordados nos procedimentos.

Conforme a Lei n. 13.140/15, a mediação pode ser aplicada como meio de solução de controvérsias e autocomposição de conflitos, nos casos que tratam de direito direitos disponíveis ou direitos disponíveis que admitam transação. No que diz respeito a direitos indisponíveis, mas transigíveis, a consenso das partes, também cabe a mediação, contudo, por força de lei, é exigida a oitiva do Ministério Público e a homologação em juízo.

Por fim, a tendência da prática da mediação depende de uma mudança de cultura e quebra de paradigmas da litigância, ainda arraigados no meio jurídico, todavia tem surtido grandes efeitos, especialmente quando aplicada nos procedimentos familiares.

\section{OFICINAS IMPLEMENTADAS NA COMARCA DE CAMBORIÚ}

Dentro desta nova possibilidade de olhar para os conflitos e da consagração positiva das soluções consensuais no âmbito dos princípios fundamentais do processo civil, imbuída da concepção de que, por trás das demandas judiciais de natureza familiar, existem por vezes, motivações não percebidas pelas partes, num primeiro momento, a juíza da $1^{\mathrm{a}}$ vara cível da Comarca de Camboriú, Dra. Karina Müller Queiroz de Souza, deu início em outubro de 2017 ao projeto "Justiça Sistêmica: vínculos de amor".

Nesse passo, insta pontuar a visão geral do referido projeto:

$\mathrm{O}$ processo, em regra, caracteriza-se como um sintoma de um conflito entre partes. Mas o conflito pode, em muitos 
casos, ser visto como uma oportunidade de crescimento, respeitando, claro, o momento e abertura de cada uma das partes envolvidas. Assim, a utilização das ferramentas de mediação, psicologia, filosofia e comunicação não violenta podem proporcionar a pacificação das relações pessoais, interpessoais, familiares, conjugais, e parentais. O estímulo para práticas restaurativas, empoderando as partes como verdadeiras protagonistas de suas histórias, mediante a facilitação do Judiciário, do Ministério Público e dos advogados, pode conduzir à restauração dos vínculos familiares e pessoais, com um novo olhar para a conflito, respeitando-se o tempo e o momento de cada um. [..] Portanto, busca-se, com a implementação das oficinas e ferramentas abaixo descritas, possibilitar às partes a efetiva resolução dos conflitos interpessoais, assim como a prevenção de novos conflitos e situações de violência com origem em temática de natureza familiar. (SOUZA, 2017, p.01).

Considerando esse posicionamento, no entendimento da magistrada, as demandas judiciais representam não apenas a tutela de um direito, mas vão além, quando as partes estendem ao processo os seus sonhos frustrados e suas maiores dores enquanto família (disputas de guarda, divórcios, busca e apreensão de criança, etc.). Além do mais, considera-se nessa visão que o Poder Judiciário também tem por missão pacificar as relações, especialmente as familiares, que constituem a base da sociedade.

\subsection{Oficina de parentalidade}

O projeto que trata da relação de pais e filhos deu-se nos Estados Unidos e Canadá, e com bases nessas iniciativas, foi trazido ao Brasil pela Juíza Vanessa Aufiero da Rocha, do Tribunal de Justiça de São Paulo, que o desenvolveu na cidade de São Vicente (SP). Diante da aceitação das partes e dos resultados positivos da aplicação em diversos Tribunais do Brasil, o Conselho Nacional de Justiça, concebeu como política institucional, de acordo com a Recomendação n. 50, 
de $05 / 05 / 2014$, que assevera:

Art. $1^{\circ}$ Recomendar aos Tribunais de Justiça e Tribunais Regionais Federais, por meio de seus Núcleos Permanentes de Métodos Consensuais de Solução de Conflitos, que:

I - adotem oficinas de parentalidade como política pública na resolução e prevenção de conflitos familiares nos termos dos vídeos e das apresentações disponibilizados no portal da Conciliação do CNJ. (BRASIL, 2014).

Não há dúvidas de que a família pós-moderna passa por constantes e inúmeras transformações, mediante os novos arranjos e, portanto, a família não tem o mesmo formato do século passado, tampouco, a definição dos papéis e posições. $\mathrm{O}$ número de divórcios cresce de forma considerável.

Com as relações desfeitas, surge a disputa pela guarda, perde-se os amigos e os parentes por afinidade, a rotina dos filhos é comprometida, o amor dá espaço a raiva, tristeza, mágoa e outros sentimentos negativos. A comunicação se torna difícil entre os pais, que muitas vezes não conseguem separar a relação de parentalidade da relação conjugal e, com isso, envolvem os filhos no conflito.

Os filhos são usados como mensageiros ou espiões dos pais, sendo comum que perguntem para a criança "escolher com quem quer ficar", ou ainda, que maculem a imagem do genitor ou genitora, dificultando o contato e a convivência.

Assim, a essência da oficina apresenta-se preventiva e pedagógica, oferecendo para as partes instruções para compreensão do caminho a ser percorrido durante o processo, e ainda, a possível conscientização da coparentalidade.

O Conselho Nacional de Justiça disponibiliza o curso em seu site, para realização online, inclusive com material didático. Entretanto, a modalidade presencial se mostra de grande valia, pois permite que as partes sejam estimuladas a momen- 
tos de reflexão, a partir de vídeos e dinâmicas. Inúmeras questões são abordadas, como por exemplo: ciclo de vida familiar, divórcio, como lidar com os sentimentos próprios e dos filhos, a comunicação com o genitor ou a genitora, prejuízos causados pelo envolvimento dos filhos nas questões referentes à ruptura, o que fazer com as diferenças, comunicação não violenta, guarda compartilhada, alienação parental, vantagens e como funcionam a conciliação e mediação, danos emocionais decorrentes do processo judicial, entre outros aspectos.

A finalidade das dinâmicas consiste em levar as pessoas, que percebam que a ruptura de uma relação conjugal não significa o fim da família, mas sim que passará a ter outro formato. Nos casos de casais com filhos, este vínculo (filhos), permanecerá para sempre, por isso frisa-se o diálogo, pois com conversa e respeito as partes podem juntas, pensar e decidir os novos arranjos familiares.

Preferencialmente, ocorre no início do processo, e antecede a audiência de conciliação prevista nos artigos 334 e 695, do Código de Processo Civil e assim, permite-se que as partes cheguem à audiência, com a consciência da pacificação e entendimento familiar, portanto, mais propensas ao diálogo.

Em Camboriú, a oficina de parentalidade iniciou no dia 09 de outubro de 2017 e até o dia 07 de maio de 2018 foram realizados 11 encontros, com a participação de 177 pessoas com processos na Vara da Família. Ao final da oficina, os participantes preenchem uma ficha de avalição, quanto ao resultado das atividades. Como forma de demonstrar a receptividade do curso, extraem-se algumas respostas das pessoas que participaram, a pergunta: "O que eu descobri com a oficina":

"Novas formas de enfrentar o processo".

"Que podemos chegar num acordo sem brigas".

"Que guarda compartilhada é participar ativamente da vida 
dos meus filhos, rotina, etc.".

"Que a família continua após o divórcio".

"Eu gostei, estava precisando de uma palavra amiga".

"Que posso mudar algumas atitudes minhas".

"Filhos serão sempre filhos".

"Vinculo familiar não acaba com a separação".

\subsection{Oficinas "Conversas de Família"}

Esta oficina foi idealizada e implementada pela Juíza Vania Petterman, da Capital e através da ferramenta da comunicação não violenta, conjuntamente com a postura sistêmica, busca oferecer a possibilidade de um novo olhar das partes para seus conflitos, onde se evidenciar emaranhamentos familiares.

As dinâmicas são realizadas por facilitadores com postura fenomenológica e sistêmica, que auxiliam os envolvidos aperceber e refletir as verdadeiras motivações que geraram o conflito no qual estão inseridos. Quando vivenciam a questão trazida ao Judiciário, nas dinâmicas sistêmicas, abre-se a possibilidade de que percebamo que está por trás do conflito, que os levou a demandar e qual a motivação do conflito, com o olhar para o que é essencial - a vida recebida dos pais e passada aos filhos, podem construir a solução para a sua demanda.

Ocorrerá, preferencialmente no início do processo, para fins de sensibilização da parte que comparecerá à audiência de conciliação ou mediação.

Em Camboriú, a oficina sistêmica iniciou no dia 17 de novembro de 2017 e até o dia 14 de maio de 2018 foram realizados 08 encontros, com a participação de 215 pessoas com processos na Vara da Família. Ao final da oficina, os participantes preenchem uma ficha de avaliação, sem identificação, extrai-se da pergunta: "O que eu descobri com a oficina": 
"Que além da raiva que temos com o parceiro, não devemos passar aos filhos".

"Que podemos unir sim os conhecimentos da alma e trabalhos terapêuticos com nossa realidade não só judiciária mas todas outras. Reconhecimento que estou fazendo meu melhor independente do resultado".

"Me ajudou muito em relação a problemas fora do meu processo".

"Valores de relacionamento de família".

"Que o respeito mútuo sempre é o melhor caminho".

"Meios de resolver problemas".

"Que não somos nós mesmos e sim um conjunto".

"Sugiro que sejam realizadas com mais frequência esse tipo de oficina".

"Mais atividades desta natureza".

"Que os acontecimentos do passado não podem influenciar nossos filhos".

"Que eu não posso fazer com que minha filha não goste do pai. Pai é sempre pai. Tenho que relevar certas coisas que ele faz".

"Que o perdão sempre vence".

"Uma nova maneira de ver a vida com relação a família".

Necessário ressaltar que a abordagem sistêmica no Judiciário encontra amparo na Resolução n. 125, do Conselho Nacional de Justiça, assim como, em consonância com Código de Processo Civil, tendo em vista que é uma abordagem que estimula as práticas consideradas adequadas para tratamento de conflitos, além de promover a humanização e pacificação social.

\subsection{Impressões das oficinas}

Apesar de não haver um levantamento empírico até o momento, percebe-se pelo contato pessoal com os participantes 
das oficinas, nas audiências de conciliação e mediação, nas quais uma ou ambas participaram das oficinas uma maior disponibilidade para dialogar, inclusive a respeito das questões emocionais que os levaram a demandar, além disso, quem participa da oficina vem para a audiência informado da importância em manter um relacionamento baseado no respeito e diálogo, bem como, conscientes dos papéis de pai e mãe independente da ruptura conjugal.

Tem-se observado nas audiências de conciliação e mediação que os participantes das oficinas relatam mudanças positivas de comportamento dos envolvidos na relação, o que de certa forma contribuí para o alívio na tensão do sistema familiar. Como exemplo, citam-se que: aprenderam a deixar os filhos fora do conflito, que evitam falar mal um do outro para os filhos, que depois da oficina o diálogo foi reestabelecido, que a outra parte cessou com ameaças/proibição de contato/ processos/chantagem, etc.

Tem-se notado, ainda, que as oficinas repercutem: não somente nos conflitos entre os antigos cônjuges ou companheiros, como também, na relação parental que é preservada e os filhos são beneficiados. As partes aprendem novas formas de lidar com os conflitos familiares, o que pode trazer paz e equilíbrio para todo o sistema familiar.

Especificamente, dentre alguns casos, citam-se três audiências realizadas com êxito conciliatório, após as duas partes participarem de umas das oficinas citadas:

Processo de regulamentação de convivência: o pai alegava na ação que a genitora não permitia o exercício de convivência com a filha de 12 anos, que estava há meses sem contato com a criança; por sua vez, a mãe alegava que a filha não queria ficar com o pai. Após a participação dos genitores nas oficinas, na audiência de conciliação, a situação fática já havia mudado, com o relato do pai, na mesma 
semana em que participou da oficina Conversas de Família, a filha manteve contato por iniciativa própria e desde então, o convívio e o diálogo foram reestabelecidos;

Processo de regulamentação de guarda: o genitor não aceitava a guarda compartilhada e seu desejo era que a mãe exercesse a guarda unilateralmente, ao participar das duas oficinas passou a entender a importância da sua participação na vida do filho e então, concordou com o exercício da guarda compartilhada;

Processo de divórcio litigioso com partilha de bens, guarda, alimentos e visita: já havia sido realizada uma audiência de conciliação e durante a instrução do processo, a genitora participou da oficina de parentalidade, sendo designada uma nova audiência de conciliação. $O$ óbice a composição consensual era a regulamentação da convivência paterna, pois a mãe achava que o pai "não tinha capacidade de cuidar da criança". Porém, após a participação na referida oficina, ela conseguiu compreender a responsabilidade de seu papel. Assim, conseguiram conversar e chegar a um consenso em todos os pontos do processo.

Além desses casos citados, outros mais têm sido vivenciados pela equipe de conciliadores e mediadores da $1^{\text {a }}$ Vara Cível da Comarca de Camboriú, percebendo-se ainda, a significativa diferença quando uma ou as duas partes não participam (pois a participação não é obrigatória).

\section{CONCLUSÃO}

Os temas aqui tratados têm contribuído para a cultura de paz e humanização do Poder Judiciário. Cada processo representa uma história de vida, geralmente carregada de dores e anseios. A instabilidade da mudança frente a ruptura da família, faz com que muitos vejam tão somente no processo a esperança para a solução dos seus conflitos.

Em respeito às partes e às relações familiares e interpessoais, o Judiciário tem buscado formas de compreender e de 
tratar os conflitos com uma visão mais humanizada. Dessa forma, tem-se um sistema judicial empático e transformativo, que ouve e atua de forma acolhedora.

Muitas vezes a percepção daquilo que conduz as pessoas ao Judiciário é que possibilita a compreensão do verdadeiro conflito. $\mathrm{O}$ processo de pedido de alimentos, às vezes, revela um filho que clama pela atenção do pai; o processo de disputa de guarda, de vez em quando, reflete o pedido de uma mãe que quer ser reconhecida como uma boa mãe pelo pai da criança; o processo de divórcio litigioso que se desdobra e não chega a um consenso, não raras as vezes é abrigo para cônjuge, que vê na ação judicial uma forma de ficar unido ao outro.

As práticas cooperativas e pacificadoras, anteriormente descritas têm contribuído para a transformação do conflito. Com a comunicação entre as partes refeita, rompe-se com entraves e obstáculos para que a real necessidade dos conflitantes seja exposta, permitindo que opções e interesses sejam discutidos, a fim de se obter a melhor solução para ambos e para o sistema familiar.

Sabe-se que não há como alcançar o intento de um Judiciário que trate todas as dores materializadas no processo, ou de técnicas infalíveis que solucionam todos os conflitos, e a reflexão deste trabalho não é nesse sentido. Mas sim, no estímulo de sobrepujar os históricos entraves, transformando a cultura do litígio para a do consenso, utilizando-se de ferramentas que auxiliam o jurisdicionado a compreender e buscar ima solução para seus conflitos.

\section{REFERÊNCIAS}

ÁVILA, Eliedite Mattos. Mediação familiar, formação de base. Florianópolis: Tribunal de Justiça do Estado de Santa Catarina, 2004.

BRASIL. Conselho Nacional de Justiça. Azevedo, André Gomma de. Manual de mediação judicial. Brasília: FUB, CEAD, 2013. 
. Lei 13.105, de 16 de março de 2015. Código de processo civil. Disponível em: <www.planalto.gov.br>. Acesso em: 6 maio 2018.

. Lei 13.140, de 26 de junho de 2015. Lei de Mediação. Disponível em: <www. planalto.gov.br>. Acesso em: 6 maio 2018. $\overline{30 \text { abr. } 2018 .}$

. Portal da conciliação e mediação. Disponível em: <cnj.jus.br>. Acesso em:

. Resolução $\mathrm{n}^{\mathrm{o}} 125$, de 29 de novembro de 2010. Dispõe sobre a política judiciária nacional de tratamento adequado dos conflitos de interesses no âmbito do poder judiciário e dá outras providências. Disponível em: $<w w w . c n j . j u s . b r>$. Acesso em: 30 abr. 2018.

CAPPELLETTI, Mauro; GARTH, Bryant. Acesso à justiça. Tradução Ellen Gracie Northfleet. Porto Alegre: Fabris, 1998.

CASTRO JUNIOR, Osvaldo Agripino de. Teoria e prática do direito comparado e desenvolvimento: Estados Unidos x Brasil. Florianópolis: Fundação Boiteux, 2002.

CINTRA, Antonio Carlos de Araújo, DINAMARCO, Cândido Rangel, GRINOVER, Ada Pellegrini. Teoria geral do processo. São Paulo: Saraiva, 2002.

EDELMAN, Joel; CRAIN, Mary Beth. O Tao da negociação. Tradução Paulo Nascimento Silva. Rio de Janeiro: Record, 1996.

FISHER, Roger; URY, William; PATTON, Bruce. Como chegar ao sim: a negociação de acordos sem concessões. Tradução Vera Ribeiro; Ana Luiza Borges. 2. ed. Rio de Janeiro: Imago, 1994.

MOORE, Christopher W. O processo de mediação: estratégias práticas para a resolução de conflitos. Tradução Magda França Lopes. 2. ed. Porto Alegre: Artmed, 1998.

PÉRES, Quitéria Tamanini Vieira. Vamos Conciliar?: elementos para o aprimoramento da desafiadora tarefa de intermediar a pacificação de conflitos. Florianópolis: Habitus, 2018.

SCHLICHTING, Arno Melo. Teoria geral do processo: concreta, objetiva, atual. Florianópolis: Momento Atual, 2002.

SERPA, Maria de Nazareth. Anais do Congresso I Congresso Brasileiro de Direito de Família: mediação e as novas técnicas de dirimir conflitos. Belo Horizonte: Del Rey, 1998.

VEZZULA, Juan Carlos. Mediação: guia para usuários e profissionais. Curitiba: Instituto de Mediação e Arbitragem do Brasil, 2001.

WARAT, Luis Aberto. O oficio do mediador. Florianópolis: Habitus, 2001.

WOLKMER, Antonio Carlos. Pluralismo jurídico: fundamentos de uma nova cultura no direito. São Paulo: Saraiva, 1997.

Recebido em: 11/05/2018

Aprovado em: 23/07/2018 